\title{
Open Innovation Platform Design: The Case of Social Product Development
}

\author{
Vanessa Roy \\ DiLab, San Diego State University \\ vroy6916@sdsu.edu \\ Kaveh Abhari \\ DiLab, San Diego State University \\ kabhari@sdsu.edu
}

\author{
Elijah Nobis \\ DiLab, San Diego State University \\ enobis0387@sdsu.edu \\ Francezca Dagoc \\ DiLab, San Diego State University \\ fdagoc@sdsu.edu
}

\begin{abstract}
Open Innovation as a new product development strategy has been used by businesses for decades. However, Social Product Development (SPD) has been recently introduced and popularized as an open innovation business model. The SPD model formalizes and monetizes the collaboration between an organization and creative communities through introducing new products and services. Either managed by intermediaries or directly by innovation sponsors, SPD platforms enable and support online innovative communities to ideate, collaborate, and network. Despite their abilities, many of these platforms do not provide fulfilling user experiences. To bridge this gap, the present study focuses on how SPD platform developers can offer more robust user interfaces (UI) and engaging user experiences (UX) alongside the six key SPD processes-social engagement, ideation, experiential communication, social validation, co-development, and cocommercialization. Building on experience and affordances theories, we offer a design framework that can more broadly inform the design and evaluation of open innovation platforms.
\end{abstract}

\section{Introduction}

Open innovation platforms play a crucial role in the formation of the new industrial revolution, known as Industry 4.0 [1]-[3]. Paramount brands such as $G E$, $B M W, P \& G$, Samsung, and $L E G O$ have successfully utilized open innovation strategies to enhance their new product development, manufacturing techniques and even marketing practices. Some open innovation models rely on individual actors to attract and develop creative ideas [4]-[6]. Among them, Social Product Development (SPD) is an open innovation model centered around collaboration between an organization and creative communities to develop and introduce new products and services [7]-[10]. Either managed by intermediaries or directly by innovation sponsors, SPD platforms enable and support online innovative communities to ideate, collaborate, and network [11]. SPD platforms allow innovation seekers to not only harvest the creative capacity of the innovation community but also validate new product concepts and service ideas.

Yet, these platforms neglect to offer a robust user experience. UI/UX design is one of the critical success factors for online communities, and the innovation community is no exception. SPD platforms face difficulties with sustainable engagement, critical ideation tools, and steep learning curves. Past research has shown that focusing on a users' needs, values, and abilities in UI/UX design encourages sustainable user engagements and enhances the quality of user contributions. Thus, further research is necessary to understand and improve the design of these platforms for better outcomes [12]. Addressing this gap, the present study investigated the cases of Edison Nation and Quirky, two SPD platforms designed to connect businesses and investors to community inventors in support of new product development. Edison Nation works directly with investors, manufacturers, and retailers that are searching for new product ideas. Likewise, Quirky assists inventors in creating products with the help of designers and manufacturers. Both platforms are designed to solicit new product ideas, support the development and selection process, connect their members, and provide feedback and updates on projects. On both platforms, new product concepts are submitted to secure portals and then processed for selection, revision, and market validation. If successful, a portion of the revenue-in the form of royalties or license agreements - is shared with the individuals who contributed to the development of the product. These products are then sold through retailers such as Amazon, Best Buy, and Bed Bath and Beyond.

The present study investigated user experience on SPD platforms using a functional affordances 
framework. A content analysis was performed using discussion forum posts on Edison Nation and Quirky related to UI/UX. To guide the content analysis, key user activities and their corresponding affordances were first identified: ideation, networking, management, and collaboration. Afterward, users' perceptions of the functional affordances offered by the platforms were examined and categorized in terms of behavioral experiences, emotional experiences, learning experiences, and social experiences. The findings revealed the importance of user experience elements in designing SPD platforms. The results contribute to the open innovation literature by shedding light on the importance of UI/UX in maintaining the performance of social innovation platforms. The study also proposes a new research process to investigate collaborative and creative communities in general.

\section{Background}

Open innovation platforms utilize both internal and external knowledge sources to accelerate new products and services development. While originally created to manage the secure flow of inbound and outbound knowledge, open innovation systems have proven to be instrumental to the innovation productivity and success of firms across the world [13]. Among these platforms, SPD platforms use social technologies and social mechanisms to democratize the innovation process in both ideation and "post-ideation" stages such as commercialization, development, marketing, and refinement [7], [14]. SPD platforms build on past renditions of open innovation models [15], [16] and break down barriers between innovation sponsors and individual collaborators. Rather than providing a structured, topdown experience, these platforms allow community members to engage with the community in a more social and fluid manner. These improvements make space for better communication and collaboration, resulting in more organic participation. This in turn fosters a more enjoyable and creative collaboration environment without limiting open ideation and social engagement [17].

On SPD platforms, innovation sponsors build a community of individual innovators, referred to as SPD users in this study. SPD users guide most of the ideation process and lead new product concept development. They are influential in improving other member ideas and helping sponsors select products to manufacture. Engaging in such activities can also nurture relationships among actors, enhance their long-term engagement with the platform beyond specific projects, and sustain their commitment to innovation generally [18].
After SPD sponsors receive input about which products should be produced, they manage the manufacturing and production processes that involve various business partners like suppliers and retailers [8]. SPD platforms create value through organizing direct sales of new products or patents, licensing intellectual property rights, and/or partnering with manufacturers and retailers; profits gained from these processes are then shared with members who participated in a successful venture [7].

While other online open innovation models generally employ a similar relational user experience [16], SPD platforms are unique in offering multidimensional user experience. In particular, SPDs engage a diverse range of users motivated by various competitive, collaborative, and community-oriented goals in a spectrum of innovation activities [9], [10], [12], [19]. Therefore, SPD presents an ideal context for observing and theorizing, open innovation participation behaviors, which are evident only to varying degrees in other open innovation models.

Though SPD platforms have gained popularity and proved to be successful for many businesses, they often contain a poorly optimized and/or underdeveloped user experience. This, in tandem with complex, mundane, or unappealing user interfaces, can both fail to provide engaging and satisfying experiences and prevent new users from entering the open innovation community all together [20]. We argue that, by better understanding the design of SPD platforms from a user experience perspective, improvements to the already popular SPD business model can lead to even greater success in the future.

\section{Method}

To evaluate the importance and impact of user experience on SPD platforms, a case study of two SPD platforms, Quirky and Edison Nation, was conducted. Past literature and community forum posts were used to identify the key experiential values of SPD platform usage. A content analysis of user posts was performed to capture user reactions to and reviews of UI/UX in their natural context. This approach led to the development of a framework explaining the relationship between user experience and SPD platform design in terms of features and affordances.

The method for collecting and analyzing the case study data included the following steps as advised by O'Riordan et al. [21]. First, the intended functions, tasks, and feature lists were examined for both platforms. Then, each platform was modeled according to its key functionalities and features. This provided relevant properties (action and interaction possibilities) into which the coded data were categorized. With these categories, comparisons could 
be drawn between Quirky and Edison Nation. Comparing two different SPD platforms provided insight into key SPD activities and allowed for greater external validity. After establishing a common language, hierarchies were applied to the properties by identifying the key affordances categories. Next, text from community forum discussions related to platform design was tagged with the corresponding affordances and experience category informed by Dewey's experience theory [22]. For Quirky, existing forum topics were utilized such as 'Ongoing UI/UX Changes'. This specific forum was already created as a space for users to leave their suggestions and reviews of the interface updates that occurred on the platform. Conversely, Edison Nation did not have an existing topic relating to UI/UX. Thus, a new topic was initiated by the authors. The responses to the discussion board came from over 200 community members. This phase resulted in the identification of corresponding experiential values with each affordance category. Lastly, each experiential value category was labelled and defined based on the empirical instances and mapped to the identified features and affordances.

\section{Case Study}

This case study involves two SPD platforms, Quirky and Edison Nation that mobilize creative individuals to innovation in the consumer product space. Both platforms allow community innovators to collaborate on new product ideas, design, development, distribution, and promotion [23], [24]. When a product successfully reaches the distribution phase, community collaborators receive a share of the revenue due to their involvement in the innovation process. This section first introduces the specifics of both cases and then discusses the findings.

\subsection{Introduction to Cases}

Quirky is an SPD platform that focuses on making innovation accessible to all [25]. It does so by utilizing its platform to operate an end-to-end consumer product development process. Ideas proposed by community members are placed into product categories by Quirky where other members with expertise can provide feedback or insight. The development process relies on ideas garnering enough community support and popularity to be considered for further development and manufacturing. Once a product has made it through the entire development process, it is then distributed though popular retailers like Amazon and Target and provides licensing options for other external partners.
Using the power of community to fuel innovation, multiple successful products have been created and are currently listed on their home site. As of 2021, Quirky has touted 1.3 million community members and 321,000 new products [26]. One product in particular, the PivotPower-"a flexible surge-protecting power strip that bends to fit every sized plug or adapter"saw over 800 contributions from community members over the course of one year [27]. It has grown to become quite popular, achieving a high rating on Amazon. As an SPD platform, Quirky's platform provides an integrated approach to open innovation. The platform's social mechanisms such as commenting, sharing, and networking create a feedback loop of opportunities for creation, innovation, and discussion that allow high community involvement in new product development.

Similarly, Edison Nation focuses on creating opportunities for community members to be a part of the innovation process. However, compared to Quirky, Edison Nation takes a different approach. Edison Nation provides its members with a "low-risk, highreward new product development process" [28]. In contrast to Quirky's more holistic approach, the process is driven primarily by the expertise of the Edison Nation team. This means that users submit their ideas with limited interaction or collaboration with the community. While Quirky invites community members to participate in product selection, Edison Nation solely consults with its innovation partners. Thus, the process of submitting an idea on Edison Nation contains more requirements and is more suitable for large branding.

Edison Nation promotes and manufactures some of its own products under the consumer brand Cloud $B$ and licenses new products with the collaboration of their community members. Like Quirky, Edison Nation distributes through popular retailers like Amazon. However, Edison Nation has over 300 other distribution partners like Bed Bath and Beyond, Black and Decker, and Proctor and Gamble [8]. Edison Nation has found success with $\$ 250$ million of sales through their partners and over 100,000 idea submissions from community creators. Though Edison Nation does not fully mirror Quirky's process, the platform has still found significant success in its implementation of the SPD model, proving to be valuable to this case study.

\subsection{Results}

The data from this case study provided consistent and comparable evidence to model key SPD activities that informed the identification of key features and affordances as well as their corresponding experiential values. Therefore, the results of the case study are 
broken into three parts: SPD key activities, features and affordances, and experiential values.

4.21. SPD Key Activities. Both Quirky and Edison Nation can be understood as networks where independent actors are socially engaged in reciprocal value exchanges to build a knowledge-driven and socially-enabled enterprise, as well as to cocreate new individual, organizational, and shared value [29]. Establishing relationships between actors first requires them to join the community and develop trusting relationships with other members. This refers to social engagement in the literature, as SPD platforms mainly use social mechanisms to engage external actors [8]. The role of social engagement is critical in building innovation communities as it allows for trust and mutual goal setting to be established.

After members join and build trust in the community of their respective SPD platform, the ideation process begins. Ideation refers to the proposing of new product ideas, collectively or individually [30], [8]. On both Quirky and Edison Nation, community members initiate the ideation process. However, ideation also occurs in response to an open call or request for ideas (RFI). While the majority of RFI are initiated by platform owners through the introduction of a problem, some external business partners propose RFI framed as innovation contests. Ideation is usually open to all community members but closely monitored and governed by internal teams. Although Quirky and Edison Nation use different mechanisms to filter and select promising ideas, both platforms benefit from community inputs. This process is called social validation [8] and can include a range of complex measures from simple community polls to sophisticated social surveys/crowdsourcing. After receiving community feedback, internal teams assess the new ideas to shortlist the best for further development or dissemination amongst external business partners.

Quirky and Edison Nation encourage collaboration when further developing and refining new ideas. Depending on the project, collaboration may be open to the entire community or limited to a certain group. In this stage, projects become more formalized and internal teams or innovation sponsors increase their involvement. SPD platform owners play the role of resource integrator by leading idea refinement, product development, prototyping, and testing [8]. The present study conceptualizes this activity as co-development-the function through which socially validated, and organizationally approved ideas are re-fined and developed into prototypes for further development and testing. Codevelopment usually involves both community members and innovation partners (e.g., in manufacturing and retailing), with actors exchanging knowledge, developing technical solutions, evaluating prototypes, and critically assessing product features and design. The active involvement of community members in co-development is a central aspect of the SPD process [8]

The final stage is the commercialization of products [30], [8]. Quirky and Edison Nation take the lead to align the product with market expectations and trends. However, both individual actors in the community and innovation partners assist the innovation sponsor in commercialization by participating in market research, testing, pricing, branding, and social sales. This study conceptualizes this activity as co-commercialization with the goal of launching marketable and profitable products; SPD sponsors rely heavily on the network actors' participation and contribution to achieve this goal [8]. These key SPD activities are enabled by the affordances provided by certain platform features. The affordances allow for interactions between users and contribute to the formation of user experiences.

4.2.2. Features and Affordances. Open innovation platforms include a variety of features that provide users with opportunities to participate, communicate, and learn. The present case study categorized these features for SPD platforms into their respective key activities. Each group of features renders key affordances: ideation, collaboration, networking, and management. Below is a discussion of these categories and a summary of the results in Table 1.

Quirky and Edison Nation platforms were designed around ideation activity. Therefore, the main group of affordances identified in this study supported ideation activities. They are enabled by a set of features such as an idea submission portal, design tools, revision options, and presentation functions. These features provide community members with ample opportunity to expand their palette of ideas. For example, users can propose new ideas while providing additional information about similar products in the market. The option to edit their ideas is also supported by these features. An opportunity to either lead the ideation process or take a less immediate approach and simply participate in the ideation process is also accounted for through these features. While Quirky and Edison Nation use different mechanisms to motivate ideation activity, those mechanisms contain similar features.

Within open innovation platforms, collaboration is closely related to ideation as it can play a vital role in new product idea selection and refinement [31]. This case study identified the role of collaboration affordances in three major activities that were discussed earlier: social validation, co-development, 
and co-commercialization. Both Quirky and Edison Nation contain features that enable collaboration between community members and thus support these key activities. These features include browsing, sorting, searching, and filtering ideas for discussion, community curation, and voting. However, Quirky offers more collaboration opportunities between external actors than the internally focused Edison Nation. Despite the differences between the cases, the findings combined give us a holistic picture of collaboration possibilities on SPD platforms.

Table 1. SPD affordances and examples of features

\begin{tabular}{|c|c|c|}
\hline \multicolumn{3}{|c|}{ KEY ACTIVITIES FEATURES EXAMPLES } \\
\hline : & $\begin{array}{l}\text { - Ideation } \\
\text { - Co-development }\end{array}$ & $\begin{array}{l}\text { - idea submission } \\
\text { - design tools } \\
\text { - presentation } \\
\text { - idea revision } \\
\text { - add/attach information } \\
\text { - search ideation opportunities } \\
\text { - search ideas for inspiration }\end{array}$ \\
\hline 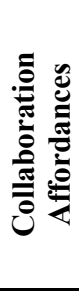 & $\begin{array}{l}\text { - Ideation } \\
\text { - Social validation } \\
\text { - Experiential } \\
\text { communication } \\
\text { - Co-development } \\
\text { - Commercialization }\end{array}$ & $\begin{array}{l}\text { - tagging } \\
\text { - join an existing project } \\
\text { - comment } \\
\text { - discussion board } \\
\text { - search } \\
\text { - vote } \\
\text { - contribute (e.g., via Q\&A, } \\
\text { survey, gamification) }\end{array}$ \\
\hline 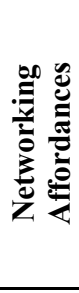 & $\begin{array}{l}\text { - Social engagement } \\
\text { - Social validation } \\
\text { - Experiential } \\
\text { communication }\end{array}$ & $\begin{array}{l}\text { - follow members } \\
\text { - share/create profile } \\
\text { - invite members } \\
\text {-search members } \\
\text { - send/receive messages } \\
\text { - join/create groups } \\
\text { - connect on social media } \\
\text { - message/comment }\end{array}$ \\
\hline 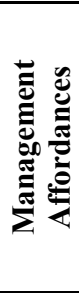 & $\begin{array}{l}\text { - Social engagement } \\
\text { - Ideation } \\
\text { - Commercialization }\end{array}$ & $\begin{array}{l}\text { - profile management } \\
\text { - portfolio/user dashboard } \\
\text {-project license management } \\
\text { - project statistic dashboard } \\
\text { - find tools } \\
\text { - feedback history } \\
\text { - notification management } \\
\text { - personalization }\end{array}$ \\
\hline
\end{tabular}

In addition to ideation and collaboration, networking affordances of SPD platforms were shown to provide the key activities social engagement, social validation, and experimental communication. Like other open innovation networks, SPD platforms are socioprofessional community spaces in which actors can connect and communicate with other members - in addition to or independent of involvement in a project. This study showed that the social engagement activity (and to some extent social validation and codevelopment activities on Quirky) benefited from networking affordances. On both platforms, networking is enabled by features such as user profiles, messaging, discussion forums, and social connections to other members (e.g., following them on the platform or social media channels). Networking affordances allow knowledge sharing throughout different product phases and indirectly promote a sense of community and encourage participation. For example, user profiles can be created, populated with contribution history, and shared to reach a larger audience and gain followers. This enhances the quality of collaboration on the platform, for example, by allowing the community members to team up with other members for joint submissions.

Both platforms also offer some profile and project management options supporting different activities. Management affordances allow users to monitor project statuses and progress as well as manage their profile and community presence. Features like notification settings, a project progress bar, and user dashboards help facilitate actor engagement, guide ideation, and enhance collaboration.

4.2.3. Experiential Values of SPD Affordances. User experience generally refers to a user's perceptions of a product, system, or service [32]. These perceptions are a set of psycho-cognitive sentiments about the experiential values of engagement or interaction with a digital artifact such as an SPD platform [14]. Hence, a positive user experience refers to a user's realization of such values, while a negative user experience refers to the recognition of their absence [33]. Accordingly, this case study attempted to identify the key experiential values associated with users' interactions and engagements with the platforms. To do so, the list of affordances was used to map the key interactions and engagements on Quirky and Edison Nation discussion forums. This analysis went beyond usability (e.g., how easy, effective, and enjoyable it is to use [34]). Table 2 summarizes the findings of this case study in terms of the relationship between affordances and experiential values. To group the findings, Dewey's experience model guided our observation of four types of experiences that result from human interactions: bodily, social, intellectual, and emotional [22]. Correspondingly, the findings were classified in a similar but further contextualized group of values: connect, learn, act, and feel. These values are respectively associated with social experiences, learning experiences, behavioral experiences, and emotional experiences. The results of the case study show that the key SPD activities and functional affordances discussed previously contribute to the development of these values.

Below is a discussion of the experiential values provided by the affordances of SPD platforms. First, social experience forms as soon as external actors join an SPD community. On both Quirky and Edison 
Nation, the case study showed users are socially engaged when they sign up and create online profiles. From there, members can personalize their profiles, follow and message other members, and see their availability and status.

Browsing other's profiles to learn about success stories, past contributions, and discussions engages users emotionally. For example, a user explained "I enjoy researching ideas, mine and others, and discovering products I never knew existed." In addition, the platform socializing, and networking features create a sense of belonging and connection between like-minded people - which, in turn, enhances the emotional experiences of users. For example, a user noted, "I am glad like-minded people like us are connected."

Users noted a sense of control and feelings of excitement and interest in discussing their emotional experiences. For example, users highlighted when the platform allowed them to interact directly with other community members, track the status of projects, learn about other users' achievements, and contribute to product development. Users attributed both good and bad emotional experiences to the management affordances identified earlier in the study. For example, the inability to search, filter, and browse successful ideas or projects was associated with negative emotions related to confusion and anxiety.

In addition to the social experience of Quirky and Edison Nation, community members frequently noted their learning experiences. For example, one user stated, "You can learn something new here every day." The case study revealed that ideation, collaboration, and networking affordances played important roles in enhancing such learning. One user explained, "I also had to teach myself how to do the 3D images and I get quicker every time, and learning a new skill is never wasted time." Here, the community member learned from the 'idea search' feature (RFI), discussions with other users, and feedback provided by internal and external actors about a problem involving 3D images. This created an encouraging learning experience and motivated them to acquire a new skill.

The case study showed that some users also share their knowledge and provide resources on SPD platforms. While knowledge-sharing enabled by collaboration affordances appeared to mainly target a specific project or RFI, networking affordances are not limited to a specific project. In addition to knowledgesharing, users learned about the SPD process and new product development through ideation and collaboration. For example, users could experiment with different product categories and ideation techniques that range from simple product concept introduction to complex 3D models.
The studied platforms not only provide a powerful learning experience but also facilitate experimentation with new ideas. By putting ideas into practice, the ideation process creates various behavioral experience possibilities that did not appear to be not limited to a specific RFI or platform. For instance, some entrepreneurs only used the platform to socially validate and refine their ideas by discussing them with other creative members of the community. For example, one user remarked, "I also spend a lot of time on here just because I like exercising my brain. I enjoy submitting designs and ideas to the community design phase." Community forum posts showed that SPD management affordances were related to behavioral experiences. For example, the organization, presentation, and navigation of ideas is crucial to ensure that users seamlessly browse and locate ideas or RFIs to contribute to. One Quirky user stated, "Another missing feature from long ago on Quirky was the ability to close out of the idea so it was no longer in the feed. This made it much easier to resume browsing the feed if you stopped for a while or logged out then back in... etc."

Quirky and Edison Nation contain several tools that allow for experiential communication. Experiential communication involves cognition when communicating with other users, especially when considering the competency of others being examined [8], [35]. Networking affordances provide multiple channels of communication and promote competencybased interactions between the users. Features like discussion boards, direct messaging, and comments facilitate collaboration during both co-development and co-commercialization, thereby enhancing behavioral experiences during these phases. Likewise, these tools potentially improve emotional experiences as they were shown to provide a sense of connection to others. Learning experience is enhanced as a result, especially when users make critical decisions like predicting the efficacy of working with other community members.

Both collaboration and management affordances of Quirky and Edison Nation have the potential to enhance behavioral experiences. For example, Quirky allows its users to browse and review ideas to participate in social validation or collaboration. However, users identified that the platform design hindered that process in some cases. A user explained: "Reviewing an idea in bits and pieces is much more difficult (especially when all of the features are in reverse chronological order) because we are constantly having to click to see more or having to click to open/view... [in the past] it was much simpler to comprehend an idea quickly because all of the information was right there on one page." 
Collaboration affordances enabling social validation and feedback were shown to a key role in emotional and learning experiences. Users remarked that features like voting allowed them to gain external approval and necessary feedback on their ideas. The users also reported a sense of excitement and fulfilment when they learned about the success of a product. The need for developing competency and gaining external approval influenced how different users reacted to the results of social validation and community feedback.

While product ideas are under refinement and development, SPD members may benefit from different collaboration affordances. Quirky allows any member to participate in activities such as pricing, naming, and feature selection. This offers various learning opportunities for users when they have access to the activity reports or project dashboard. Reports help users to learn more efficiently and in turn make more informed decisions in the future. Our study revealed that the dashboards and reports also have both emotional and behavioral values, as users remarked they offered a sense of control and drove action. For example, a user commented, "[We need] downloadable reports of influence earned, per product, and earnings per product."

Finally, when an idea is selected for production, Quirky and Edison Nation invite community members - individually or collectively - to participate in and assist with commercializing and launching the final product. This involvement is supported by collaboration affordances and enhanced by management affordances. The case study revealed that when users feel consistently updated throughout this part of the process via dashboards or other reporting mechanisms, their emotional experiences are enhanced. Thus, because product commercialization can take a significant amount of time, SPD platforms should prioritize communicating the project status with community members regularly.

Table 2. Examples of experiential values in relationship with SPD affordances

\begin{tabular}{|c|c|c|c|c|}
\hline \multirow{2}{*}{ AFFORDANCES } & \multicolumn{4}{|c|}{ EXPERIENTIAL VALUES } \\
\hline & CONNECT & LEARN & ACT & FEEL \\
\hline$\overline{\text { Ideation }}$ & $\begin{array}{l}\text { social inspiration: } \\
\text { inspired by success } \\
\text { stories shared by } \\
\text { community members }\end{array}$ & $\begin{array}{l}\text { ideation challenge: } \\
\text { review RFIs, compare } \\
\text { ideas, receive feedback } \\
\text { on ideas }\end{array}$ & $\begin{array}{l}\text { ideation in action: } \\
\text { submit, present, promote, } \\
\text { and discuss new product } \\
\text { ideas }\end{array}$ & $\begin{array}{l}\text { ideation recognition: } \\
\text { receive public badges for } \\
\text { submitting new ideas }\end{array}$ \\
\hline Collaboration & $\begin{array}{l}\text { social connection: } \\
\text { connect to likeminded } \\
\text { people for join ideation or } \\
\text { future collaboration }\end{array}$ & $\begin{array}{l}\text { collaboration challenge: } \\
\text { observe collaboration } \\
\text { process and its outcomes }\end{array}$ & $\begin{array}{l}\text { collaboration in action: } \\
\text { brainstorm, discuss and } \\
\text { co-create ideas }\end{array}$ & $\begin{array}{l}\text { collaboration } \\
\text { recognition: receive } \\
\text { sharable recognition for } \\
\text { successful collaboration }\end{array}$ \\
\hline Networking & $\begin{array}{l}\text { social identification: } \\
\text { create a profile, browse } \\
\text { other users' profile }\end{array}$ & $\begin{array}{l}\text { socio-professional } \\
\text { learning: browse } \\
\text { potential collaborators' } \\
\text { profiles and their skill }\end{array}$ & $\begin{array}{l}\text { networking in action: } \\
\text { invite collaborators or } \\
\text { join collaborative projects }\end{array}$ & $\begin{array}{l}\text { community building: } \\
\text { allow users to create } \\
\text { interest groups }\end{array}$ \\
\hline Management & $\begin{array}{l}\text { social coordination: } \\
\text { manage user profile and } \\
\text { connection within the } \\
\text { community }\end{array}$ & $\begin{array}{l}\text { knowledge management: } \\
\text { allow users create and } \\
\text { download reports and use } \\
\text { cases }\end{array}$ & $\begin{array}{l}\text { monitoring/tracking: } \\
\text { allow users to track their } \\
\text { rewards and projects' } \\
\text { progress }\end{array}$ & $\begin{array}{l}\text { user empowerment: offer } \\
\text { personalization options } \\
\text { and portfolio } \\
\text { management }\end{array}$ \\
\hline
\end{tabular}

\section{Discussion}

This study first identified the UI/UX features associated with the following key SPD activities: social engagement, ideation, social validation, experiential communication, co-development, and cocommercialization. Then, SPD platform affordances and their enabling features were modeled: ideation (e.g., search, design, spark, submission), networking (e.g., forums, friends), management (e.g., dashboard, help, guide), and collaboration (e.g., co-design, voting). Next, the associations between these affordances and four key groups of user experiences were identified (Figure 1). In particular, this study examined how users perceive the values of different functional affordances offered by these elements in terms of act (e.g., to create, be efficient), feel (e.g., feel valued, have fun), learn (e.g., to develop skills, test ideas), and connect (e.g., to connect to likeminded people). These associations were used to explain the relationship between SPD platform design and user experiences, thereby proposing a more integrated, holistic approach to improving SPD user experiences.

This study contributes to the literature by offering a more practical approach to understand user experience on SPD platforms and inform SPD platform design from this perspective. The current understanding of SPD UI/UX is mainly informed by open innovation literature. Considering the key differences noted in this study, these findings can provide a fresh insight into analyzing the differences between user experience on typical open innovation 
platforms and SPD platforms. This work also contributes to the operationalization of user experience on SPD platforms, informing future evaluations of user experience. The reflections from SPD users utilized in this study reveal that user experience management should be considered the core of open innovation platform design and governance.

Users indicated they felt engaged in SPD when platforms provided compelling experiences aligned with key SPD activities. These findings offer guidance for improvements SPD platform owners can make to increase the functionality and utility of their platforms. By understanding the functional affordances responsible for key user experiences, SPD platforms can be more selective in refining the UI/UX features associated with those affordances. Although the limitations of a case study method do not allow us to fully generalize our findings, the following recommendations exemplify how our approach may inform future open innovation platform design.
The results show that users are more concerned with the ideation and management affordances than collaboration or networking affordances. For example, in the case of Quirky, users primarily discussed ideation related features as the best way to enhance overall user experience. While the platform focused on adding new functionalities to the ideation phase, users insisted on simplification (removing features) or addition of features such as filtering and sorting to streamline the process. Moreover, the users frequently discussed management affordances as the sources of both pain and gain. This can be attributed to their perceived sense of control. For example, lack of features reporting the project status, especially during the commercialization phase, was one source of negative user experience. Similarly, providing users with options to review project portfolios or personal contribution dashboards was identified to contribute to positive user experience.

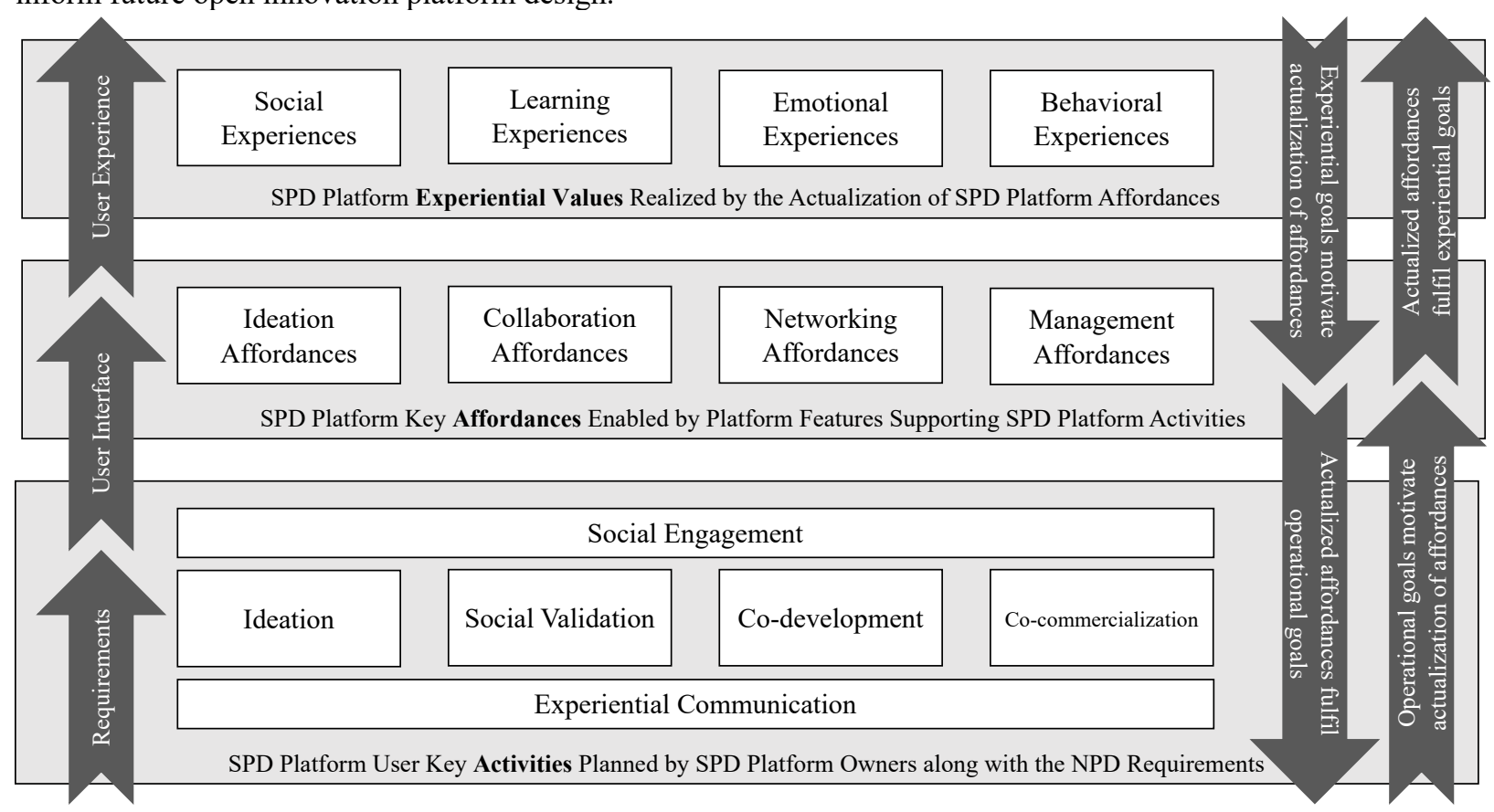

Figure 1. User experience formation on SPD platform

This case comparison also showed that behavioral experiences play a critical role in differentiating user experience on SPD platforms. This role was shown to be especially pronounced when the platform allowed more action-oriented participation (e.g., adding 3D rendering for product ideas or searching the web to find comparable products). Users reported better behavioral experiences when the platform afforded idea creation and development rather than idea communication alone. Therefore, we argue in favor of prioritizing ideation features that support creating and developing ideas collaboratively.
Collaboration and networking affordances, surprisingly, played less prominent roles in user total experience formation compared with ideation and management affordances. This requires further empirical analysis and quantitative investigation. One justification could be that the SPD platforms' reward systems are centered around the success of ideation. On these platforms, ideation success is rewarded directly by licensing agreement or profit sharing, while ideation failure is indicated by formal feedback. However, there appeared to be limited incentives for helping and networking with other users. Hence, it is 
reasonable that users prioritized ideation and management to maximize their gain. Nevertheless, SPD platforms are not purely utilitarian, and many users join them because of intrinsic and altruistic motivations. This case study suggests that collaboration and networking affordances should be revisited alongside ideation and management in order to provide more positive experiences for users. Ideation, especially when it requires more active participation, could benefit from healthy social engagement and collaborative problem-solving. Similarly, management affordances should not be limited to tracking ideation activities but also include possibilities to monitor and manage networking activities, socio-professional connections, and collaboration opportunities and history.

In summary this study confirms that a key strategy to engage users in SPD is to provide compelling user experience. Failure to do so may limit user participation and contributions. Table 3 summarizes some practical recommendations for improving SPD platforms. These recommendations are also applicable in other open innovation platforms or similar creative communities that engage and manage individual actors by the same mechanisms.

Table 3. Recommendations

\begin{tabular}{|c|c|c|c|c|}
\hline ACTIVITIES & $\begin{array}{l}\text { SOCIAL } \\
\text { EXPERIENCES }\end{array}$ & $\begin{array}{l}\text { LEARNING } \\
\text { EXPERIENCES }\end{array}$ & $\begin{array}{l}\text { BEHAVIORAL } \\
\text { EXPERIENCES }\end{array}$ & $\begin{array}{l}\text { EMOTIONAL } \\
\text { EXPERIENCES }\end{array}$ \\
\hline Social Engagement & $\begin{array}{l}\text { View other users' profile } \\
\text { and status (e.g., bio, skills, } \\
\text { availability, achievements, } \\
\text { networks) }\end{array}$ & $\begin{array}{l}\text { Include projects' } \\
\text { portfolios and launched } \\
\text { products' reports (e.g., } \\
\text { customer reviews) }\end{array}$ & $\begin{array}{l}\text { Allow different } \\
\text { membership tiers and } \\
\text { profile personalizing }\end{array}$ & $\begin{array}{l}\text { Features successful } \\
\text { projects and successful } \\
\text { members }\end{array}$ \\
\hline Ideation & $\begin{array}{l}\text { Allow social ideation (i.e., } \\
\text { ideas emerged as the } \\
\text { result of open discussion } \\
\text { around a problem) }\end{array}$ & $\begin{array}{l}\text { Include ideation tools such } \\
\text { 'use case' to allow users } \\
\text { use case feature to better } \\
\text { illustrate user ideas }\end{array}$ & $\begin{array}{l}\text { Add sort and filter feature } \\
\text { to view only targeted 'idea } \\
\text { search' (RFI) }\end{array}$ & $\begin{array}{l}\text { Break down complex idea } \\
\text { search into smaller } \\
\text { multiple tasks }\end{array}$ \\
\hline $\begin{array}{l}\text { Experiential } \\
\text { Communication }\end{array}$ & $\begin{array}{l}\text { Enable transparent and } \\
\text { open communication } \\
\text { between users, under } \\
\text { project/RFI topics }\end{array}$ & $\begin{array}{l}\text { Offer knowledge } \\
\text { management system to } \\
\text { document community } \\
\text { memory/best practices }\end{array}$ & $\begin{array}{l}\text { Provide members with } \\
\text { multiple methods of } \\
\text { communications }\end{array}$ & $\begin{array}{l}\text { Reward effective } \\
\text { communication (e.g., like, } \\
\text { badges) }\end{array}$ \\
\hline Social Validation & $\begin{array}{l}\text { View the statistics of } \\
\text { community participation, } \\
\text { the diversity opinions, and } \\
\text { internal actors' decisions }\end{array}$ & $\begin{array}{l}\text { Provide product } \\
\text { evaluation results to both } \\
\text { community and innovators }\end{array}$ & $\begin{array}{l}\text { Enable social voting } \\
\text { system to seek feedback } \\
\text { beyond the community }\end{array}$ & $\begin{array}{l}\text { Display the users' } \\
\text { contribution to social } \\
\text { validation }\end{array}$ \\
\hline Co-development & $\begin{array}{l}\text { Allow for searching, } \\
\text { finding, and connecting to } \\
\text { potential collaborators }\end{array}$ & $\begin{array}{l}\text { Provide brainstorming, } \\
\text { voting and survey tools }\end{array}$ & $\begin{array}{l}\text { Allow feedback or direct } \\
\text { contribution to the } \\
\text { different phases of co- } \\
\text { development }\end{array}$ & $\begin{array}{l}\text { Recognize users' } \\
\text { participation by adding } \\
\text { their name or awarding } \\
\text { badges }\end{array}$ \\
\hline $\begin{array}{l}\text { Co- } \\
\text { commercialization }\end{array}$ & $\begin{array}{l}\text { Include social promotion } \\
\text { and social sales options }\end{array}$ & $\begin{array}{l}\text { Access successful } \\
\text { products' profiles }\end{array}$ & $\begin{array}{l}\text { Allow users to participate } \\
\text { in activities such as } \\
\text { promotion, pricing, and } \\
\text { package design. }\end{array}$ & $\begin{array}{l}\text { Recognize users' feedback } \\
\text { and contributions to } \\
\text { branding and promotion } \\
\text { activities }\end{array}$ \\
\hline
\end{tabular}

\section{Conclusions and Future Research}

Experiential values of a digital artifact can dazzle users' senses, touch their hearts, stimulate their minds, and inspire their actions. This study evaluated this claim in SPD settings with the hope of contributing to open innovation literature. The observation and content analysis of Quirky and Edison Nation users' comments helped us to identify the key SPD affordances and their associated features. We also analyzed the experiential values of these platforms through identifying the relationships between features and affordances. Accordingly, we developed a theoretical foundation and documented a practical perspective for SPD UI/UX design and evaluation.
Despite its limitations, this study opens several research avenues. The results presented in this work were limited to a study of two cases of SPD platforms. Therefore, future research should use new cases of SPD platforms to extend and validate these findings. These data were also limited to user unmoderated and archived discussions pertaining to UI/UX topics. Therefore, collecting additional data through experimentations (e.g., A/B testing), interviews, and surveys would further advance this inquiry. Likewise, the case study findings were contextually based on a limited number of users' reactions to existing or proposed UI/UX changes. Therefore, including more objective data like user interrelations with different UI/UX elements could offer a more holistic and generalizable explanation of user behavior. While this 
study is limited to SPD platforms, future studies should replicate this study in other open innovation settings such as innovation marketplaces, customer innovation forums, and open-source software communities. Additionally, this study was limited to key functional affordances and key SPD activities. Hence, future research should also investigate different forms of affordances perceived by users themselves. Lastly, conducting experiments would also help validate the causal relationships between the identified affordances and user experiences. This along with examining and refining the concepts proposed here in other settings could help researchers to develop a more generalizable framework, allowing open innovation platforms that are designed, implemented, and governed more effectively.

\section{References}

[1] M. Anshari and M. N. Almunawar, "Adopting open innovation for SMEs and industrial revolution 4.0," $J$. Sci. Technol. Policy Manag. 2021.

[2] M. F. Mubarak, S. Tiwari, M. Petraite, M. Mubarik, and R. Z. Raja Mohd Rasi, "How Industry 4.0 technologies and open innovation can improve green innovation performance?," Manag. Environ. Qual. An Int. J., vol. 32, no. 5, pp. $1007-$ 1022, 2021, doi: 10.1108/MEQ-11-2020-0266.

[3] M. F. Mubarak and M. Petraite, "Industry 4.0 technologies, digital trust and technological orientation: What matters in open innovation?," Technol. Forecast. Soc. Change, vol. 161, p. 120332,2020 .

[4] G. von Krogh, S. Haefliger, S. Spaeth, and M. W. Wallin, "Carrots and rainbows: Motivation and social practice in open source software development," MIS Q., vol. 36, no. 2, pp. 649676, 2012, doi: 10.2307/41703471.

[5] T. Liao and $\mathrm{K} . \mathrm{Xu}$, "A process approach to understanding multiple open source innovation contests - Assessing the contest structures, execution, and participant responses in the android developer challenges," Inf. Organ., vol. 30, no. 2, p. 100300, 2020, doi: 10.1016/j.infoandorg.2020.100300.

[6] A. Dingler and E. Enkel, "Socialization and innovation: Insights from collaboration across industry boundaries," Technol. Forecast. Soc. Change, vol. 109, pp. 50-60, 2016.

[7] T. Strohmann, L. Höper, and S. Robra-Bissantz, "Design Guidelines for Creating a Convincing User Experience with Virtual In-vehicle Assistants," Proc. 52nd Hawaii Int. Conf. Syst. Sci., 2019, doi: 10.24251/hicss.2019.580.

[8] K. Abhari, E. J. Davidson, and B. Xiao, "Modeling Social Product Development Process, Technology, and Governance," IEEE Trans. Eng. Manag., pp. 1-14, 2020, doi: 10.1109/tem.2020.2973234

[9] M. C. Annosi, G. Marzi, F. Ciampi, and R. Rialti, "An Ambidextrous Approach to Practice-Based Innovation for Social Product Development: Lessons From A Dutch Company," IEEE Trans. Eng. Manag., pp. 1-12, 2020.

[10] H. Forbes, D. Schaefer, J. Panchal, and J. Han, "A Design Framework for Social Product Development," IEEE Trans. Eng. Manag., vol. PP, pp. 1-12, 2019.

[11] K. Abhari, B. Xiao, and E. Davidson, "Communication in coinnovation networks: A moderated mediation model of social affordances, social experience, and desire for learning," in Lecture Notes in Computer Science, 2017, vol. 10293 LNCS, pp. 139-153, doi: 10.1007/978-3-319-58481-2 12.

[12] K. Abhari, E. J. Davidson, and B. Xiao, "Inventing Together: The Role of Actor Goals and Platform Affordances in Open
Innovation," J. Assoc. Inf. Syst., 2021

[13] H. Forbes and D. Schaefer, "Social Product Development: The Democratization of Design, Manufacture and Innovation," Procedia CIRP, vol. 60, pp. 404-409, 2017.

[14] K. Abhari, E. Davidson, and B. S. Xiao, “'Experience First': Investigating Co-creation Experience in Social Product Development Networks," AIS Trans. Human-Computer Interact., vol. 11, no. 1, pp. 1-32, 2019.

[15] J. A. Chisty, "Innovation in Co-Creation Practices: An Exploratory Study," Carleton University, 2011.

[16] A. Peterson and D. Schaefer, "Social Product Development: Introduction, Overview, and Current Status," in Product Development in the Socio-sphere, vol. 9783319074, no. September, D. Schaefer, Ed. Cham: Springer, 2014, pp. 1-33.

[17] M. Paulini, P. Murty, and M. L. Maher, "Design Processes in Collective Innovation Communities: a Study of Communication," CoDesign, vol. 9, no. 2, pp. 90-112, 2013.

[18] J. Füller, K. Hutter, J. Hautz, and K. Matzler, "User Roles and Contributions in Innovation-Contest Communities," $J$. Manag. Inf. Syst., vol. 31, no. 1, pp. 273-308, 2014.

[19] C. Han and M. Yang, "Stimulating Innovation on Social Product Development: An Analysis of Social Behaviors in Online Innovation Communities," IEEE Trans. Eng. Manag., pp. 1-11, 2020, doi: 10.1109/tem.2019.2955073.

[20] T. Kohler and M. Nickel, "Crowdsourcing business models that last," J. Bus. Strategy, vol. 38, no. 2, pp. 25-32, Apr. 2017.

[21] S. O'Riordan, J. Feller, and T. Nagle, "Exploring The Affordances Of Social Network Sites: An Analysis Of Three Networks," 2012.

[22] J. Dewey, Experience and Nature. Dover Publications, 1958.

[23] D. Wu, D. W. Rosen, J. H. Panchal, and D. Schaefer, "Understanding Communication and Collaboration in Social Product Development Through Social Network Analysis," J. Comput. Inf. Sci. Eng., vol. 16, no. 1, pp. 1-10, 2016.

[24] D. Schaefer, Social Product Development: Introduction, Overview, and Current Status, July. 2014.

[25] F. Piller, "ten-reasons-why-i-consider-quirkycom-as-best-incrowdsourcing-and-open-innovation," 2010 . .

[26] Quirky, "quirky.com,” 2021. .

[27] Chris Raymond, "How Quirky Turns Ideas Into Inventions," Popular Mechanics, 2014.

[28] F. von Briel and C. Schneider, "A Taxonomy of Web-Based Inbound Open Innovation Initiatives," 18th Am. Conf. Inf. Syst., no. 1, 2012, Accessed: Feb. 25, 2019.

[29] S. M. Lee, D. L. Olson, and S. Trimi, "Co-innovation: Convergenomics, Collaboration, and Co-creation for Organizational Values," Manag. Decis., vol. 50, no. 5, pp. 817-831, 2012, doi: 10.1108/00251741211227528.

[30] B. Bernstein and P. J. Singh, "An integrated innovation process model based on practices of Australian biotechnology firms," Technovation, vol. 26, no. 5-6, pp. 561-572, 2006.

[31] K. Abhari, E. J. Davidson, and B. Xiao, "Co-Innovation Platform Affordances: Developing a Conceptual Model and Measurement Instrument," Ind. Manag. Data Syst., vol. 117, no. 5, pp. 873-895, 2017, doi: 10.1108/IMDS-05-2016-0156.

[32] W. J. Orlikowski and S. V Scott, "the Algorithm and the Crowd: Considering the Materiality of Service Innovation.," MIS Q., vol. 39, no. 1, pp. 201-216, 2015.

[33] A. Bhattacherjee, G. P. Logistics, and M. Operations, "Understanding Changes in Belief and Attitude Toward Information Technology Usage: A Theoretical Model and Logitudinal Test," MIS Q., vol. 28, no. 2, pp. 229-254, 2004.

[34] J. Preece, Y. Rogers, and H. Sharpe, "Interaction Design: beyond human-computer interaction. 4th ed.," p. 400, 2019.

[35] K. Abhari and E. J. Davidson, "Creative Co-production: The Adaption of an Open Innovation Model in Creative Industries," in Information Systems and Management in Media and Entertainment Industries, Springer, 2016, pp. 119-130. 